\title{
CHEMICAL RELEASERS OF NECROPHORIC BEHAVIOR IN ANTS
}

\author{
By E. O. Wilson, ${ }^{1}$ N. I. DURLACH, ${ }^{2}$ AND L. M. ROTH ${ }^{3}$ \\ INTRODUCTION
}

One of the more conspicuous and stereotyped patterns of social behavior exhibited by ants is the transport of dead members of the colony from the nest to the refuse piles (McCook, 1882; Wheeler, 1926). Because of the obvious simplicity of this "necrophoric" response and the ease with which it can be experimentally elicited, it has proven to be one of the forms of ant behavior most amenable to physiological analysis. In the present paper are presented the results of a preliminary study of the response in the myrmicine ants Pogonomyrmex badius (Latreille) and Solenopsis saevissima (Fr. Smith), in which special attention has been paid to the releasing stimuli.

\section{DESCRIPTION OF THE BEHAVIOR}

When the corpse of an adult Pogonomyrmex badius worker that has been allowed to decompose in the open air for a day or more is placed inside the nest or outside near the nest entrance, the first sister worker to encounter it ordinarily investigates it briefly by repeated antennal contact, then picks it up and carries it directly away from the nest toward the refuse piles. Under the conditions existing during the present study, most of the refuse piles of the captive colonies were located less than one meter from the nest entrance along the back wall of a closed foraging arena. This distance was evidently inadequate to allow the rapid consummation of the corpse removal response, for workers bearing corpses frequently wandered for many minutes

1 Biological Laboratories, Harvard University, Cambridge Mass.

2 Lincoln Laboratory, Lexington, Mass.

3 U. S. Army Quartermaster Research and Engineering Center, Natick, Mass. 
back and forth along the back wall before dropping their burdens on the refuse piles. Others were seen to approach the back wall unburdened, to pick up corpses already on the piles, and to transport them in similarly restless fashion before re-depositing them.

It is a curious fact that in nature such "cemeteries" are rare or non-existent in the vicinity of Pogonomyrmex badius nests. During field studies conducted in northern Florida and southern Alabama, it was found that corpses removed from the nests are carried only a short distance beyond the rim of the nest crater before being dropped. Once abandoned, they are soon collected by scavenging workers of the dolichoderine species Conomyrma pyramica (Roger), one of the dominant ants occurring with P. badius in its native range. The swift Conomyrma workers patrol the vicinity of the Pogonomyrmex nests in large numbers during the day, and their activities apparently prevent the accumulation of Pogonomyrmex dead. It is not known whether other ant species assume this role outside the range of Conomyrma.

In the laboratory most injured and dying Pogonomyrmex badius workers leave the nest interior before succumbing. These individuals are usually found wandering through the foraging arena, unattended by sister workers. If similar behavior is exhibited in nature, it can safely be inferred that the removal of corpses is thus accomplished in large part by the dying ants themselves, as their last act as living workers. Under laboratory conditions queens and some larger major workers remain within the nest while dying. Several times it was observed that the bodies of these individuals remained in the nest for three days, during which they were frequently licked and moved about by the workers. After that time they were removed to the refuse piles.

\section{EXPERIMENTS}

Assay of decomposition products. The following experiment was designed to determine whether certain substances separated from the body of the corpse could by themselves elicit necrophoric behavior. A square of filter paper six 
millimeters on the side was daubed with an acetone extract of Pogonomyrmex badius worker corpses and placed, in company with five untreated control squares, inside the foraging arena five centimeters from the nest entrance. In three separate trials, the treated squares were picked up within five minutes by the first workers to encounter them and transported directly to the refuse piles. In their reaction to the treated squares and in their locomotory patterns during transport, the workers appeared to behave in the same fashion as toward worker corpses. No immediate reaction to the control squares was noted, and they were not moved significantly from their original positions during the first several hours. In only one case was a control square transported in the direction of the refuse piles during the course of the first twenty-four hours.

A similar response was also evoked by objects other than paper squares. Seeds, for example, which ordinarily would be ignored or carried into the nest for storage, when daubed with the extract were carried to the refuse pile. The most dramatic example of the potency of this extract as a releaser occurred on three occasions when the objects chosen for experiment were live workers. Despite the fact that these ants were moving around under their own power and providing socially significant stimuli, they were treated by their sisters as corpses. However, unlike authentic corpses they would allow themselves to be carried to the refuse pile only to rise again and return to the nest! The cycle was observed to occur repeatedly during periods of one to two hours. During transport, the workers folded their appendages in the "pupal" posture usually taken by normal workers being carried to nest sites.

An attempt was next made to determine whether the chemical releasers could be removed from worker bodies by leaching so as to modify the response of living workers to the bodies. Three worker corpses were placed in bottles containing $50 \mathrm{cc}$. of acetone for periods of one to three weeks, then thoroughly dried and presented in succession to living workers in the manner described above. The behavior toward these treated bodies was markedly different from that shown toward untreated corpses. Instead 
of transporting them away from the nests, the workers began to lick and chew them vigorously. One was carried quickly into the nest; the other two were dragged back and forth for short distances near the nest entrance. Several untreated corpses placed around the leached bodies were at the same time carried directly off to the refuse piles. One of the leached bodies was recovered several minutes after its introduction, daubed with corpse extract, and reintroduced. The same workers that had been licking it previously now carried it directly to the refuse piles. The other two leached bodies were left in position to observe their subsequent treatment. One was dismembered by the living workers; both were carried away from the nests only after forty minutes or longer.

The paper-square test described previously was next employed to test a few common fat and protein decomposition products and related compounds obtained as chemical reagents. The following substances produced no detectable response, either in saturated or dilute solutions: ammonium sulfide, di-alpha-amine. Weak to moderate alarm behavior, followed occasionally by digging behavior ${ }^{1}$, was evoked by the following substances: phenylethylamine, triethanolamine, phenol, n-valeric acid, n-caproic acid, n-caprylic acid, n-butyric acid, formic acid. The only substance tested that released the necrophoric response, or anything resembling it, was oleic acid. In repeated trials, oleic acid daubed onto paper squares and other small neutral objects invariably elicited a behavioral response from $P$. badius indistinguishable from that evoked by worker corpses.

On the assumption that oleic acid, or a related compound, is a principal natural releaser of the necrophoric response, an attempt was made to separate and analyze the longchain fatty acids found in Pogonomyrmex worker corpses. Infrared spectra were prepared from a crude extract of about 200 dead bodies of P. barbatus (Fr. Smith). These spectra were made from a sample in $\mathrm{CCl} 4$ and from a liquid film after the carbon tetrachloride was evaporated.

$1 \mathrm{~A}$ fuller account of alarm and digging behavior, and of the various stimuli that release these linked responses, has been presented elsewhere (Wilson, 1959). 
The spectra indicated the presence in the crude extract of an ester (the principal compound) and a fatty acid. An attempt was made to separate the fatty acid from the mixture. The solvent of the original solution was evaporated and the residue dissolved in ether which was then washed with dilute $\mathrm{Na}_{2} \mathrm{CO}_{3}$. The alkaline wash containing the sodium salt of the fatty acid was separated from the ether solution containing the ester. The infrared spectrum of the ether solution compared well with the original crude material, indicating that the ester had been removed. The alkaline wash containing the $\mathrm{Na}$ salt of the fatty acid was acidified with dilute $\mathrm{HCl}$ and extracted with ether. The infrared spectrum of this ether extract indicated a fatty acid though the spectrum was not sufficiently distinctive to identify the compound specifically. In a series of tests using treated and untreated (control) paper squares, it was found that both the fatty acid and the ester evoked the necrophoric response. However, the fatty acid appeared to be the more effective of the two, in that it tended to release the response more quickly and to induce transport of the treated squares over greater distances. It was further observed that the acid-daubed squares were as a rule transported further away from the nest entrance during initial transport. Also, the ester-daubed squares frequently caused an initial mild alarm reaction that delayed the necrophoric response even more, whereas the acid-daubed squares were never observed to do so. It is possible that complete separation of the acid and ester was not obtained and that contamination of the ester fraction with the acid could account for the equivocal results.

Use of another test species. An attempt was next made to determine whether the fatty acid obtained from Pogonomyrmex barbatus would release necrophoric behavior in a phylogenetically remote ant species, Solenopsis saevissima (Fr. Smith). Four paper squares daubed with the acid were inserted, along with four control squares, into the brood chamber of an artificial nest containing a colony of $S$. saevissima. Within 25 minutes all four of the treated squares had been carried out and placed at the edge of the nest. Soon afterward the control squares were brought 
out and dropped at the same place. Five hours later all of the treated squares had been moved to a position about twenty centimeters beyond the nest edge. A saevissima worker was later seen carrying a treated square back and forth in the restless fashion commonly seen in workers of this species carrying corpses.

Assay of extract from another insect species. To determine whether fatty extracts of corpses of another insect species causes the necrophoric response in Pogonomyrmex badius, extracts from meal worms (Tenebrio molitor) allowed to decompose in open air for two weeks were tested in the usual fashion. Treated paper squares were carried promptly to the refuse piles by the Pogonomyrmex workers, whereas control squares were left untouched for the first several hours. The behavior of the ants toward the treated squares seemed identical to that shown toward squares treated with the extract of Pogonomyrmex corpses.

\section{CONCLUSIONS}

Pogonomyrmex badius workers utilize a relatively limited range of stimuli in "recognizing" insect corpses. Morecver, the stimuli appear to be exclusively chemical in nature. One of the principal chemical releasers is evidently the fatty acid that accumulates in the bodies of sister workers allowed to decompose in open air. An ester may also play a secondary role. Of several chemical compounds tested commonly found in insect corpses, oleic acid was the only substance which caused the ants to behave as they do toward dead insect bodies. Whether other substances present in ant corpses (and those of other animals) release the necrophoric response is not known. It may be suggestive that the common smaller molecular products of decomposition thus far tested have all produced neutral or alarm behavior without any element of necrophoresis. It is also noteworthy that long-chain fatty acids are chemically among the most stable and least volatile of fat and protein decomposition products and hence tend to accumulate disproportionately in insect corpses. As a result these substances have the potential to serve as efficient signals of the presence of aging corpses, as opposed to freshly 
killed and edible insect prey. Finally, the fact that the fatty acid from Pogonomyrmex barbatus corpses induced typical necrophoric behavior in both $P$. badius and Solenopsis saevissima workers suggests that this behavior and its natural releasers may be widespread in the ants.

\section{Literature Cited}

McCook, H. C.

1882. The honey ants of the Garden of the Gods and the occident ants of the American Plains. J. B. Lippincott.

WHEELER, W. M.

1926. Ants, their structure, development and behavior. Columbia University.

Wilson, E. O.

1959. A chemical releaser of alarm and digging behavior in the ant Pogonomyrmex badius (Latrelle). Psyche, 65:41-51 

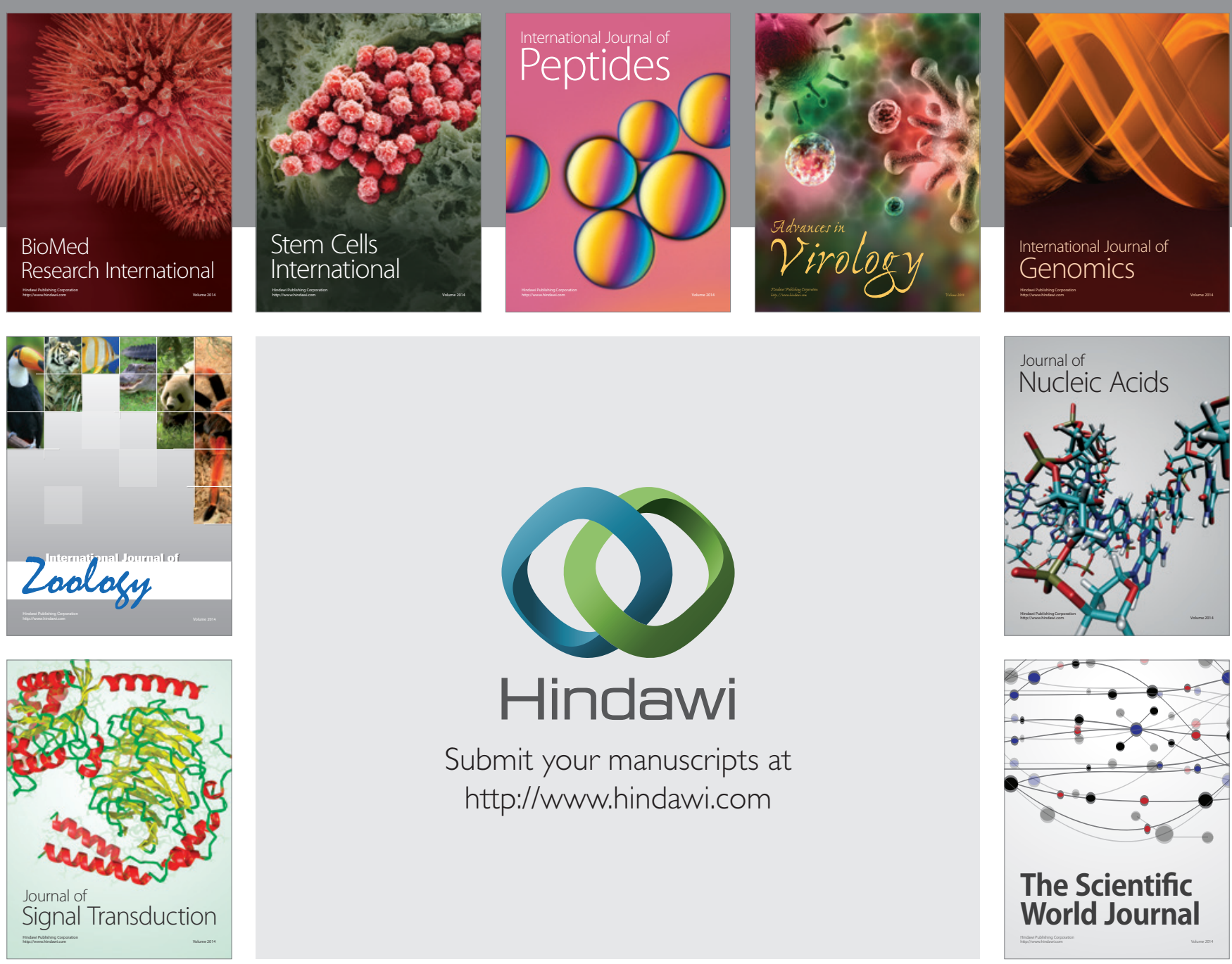

Submit your manuscripts at

http://www.hindawi.com
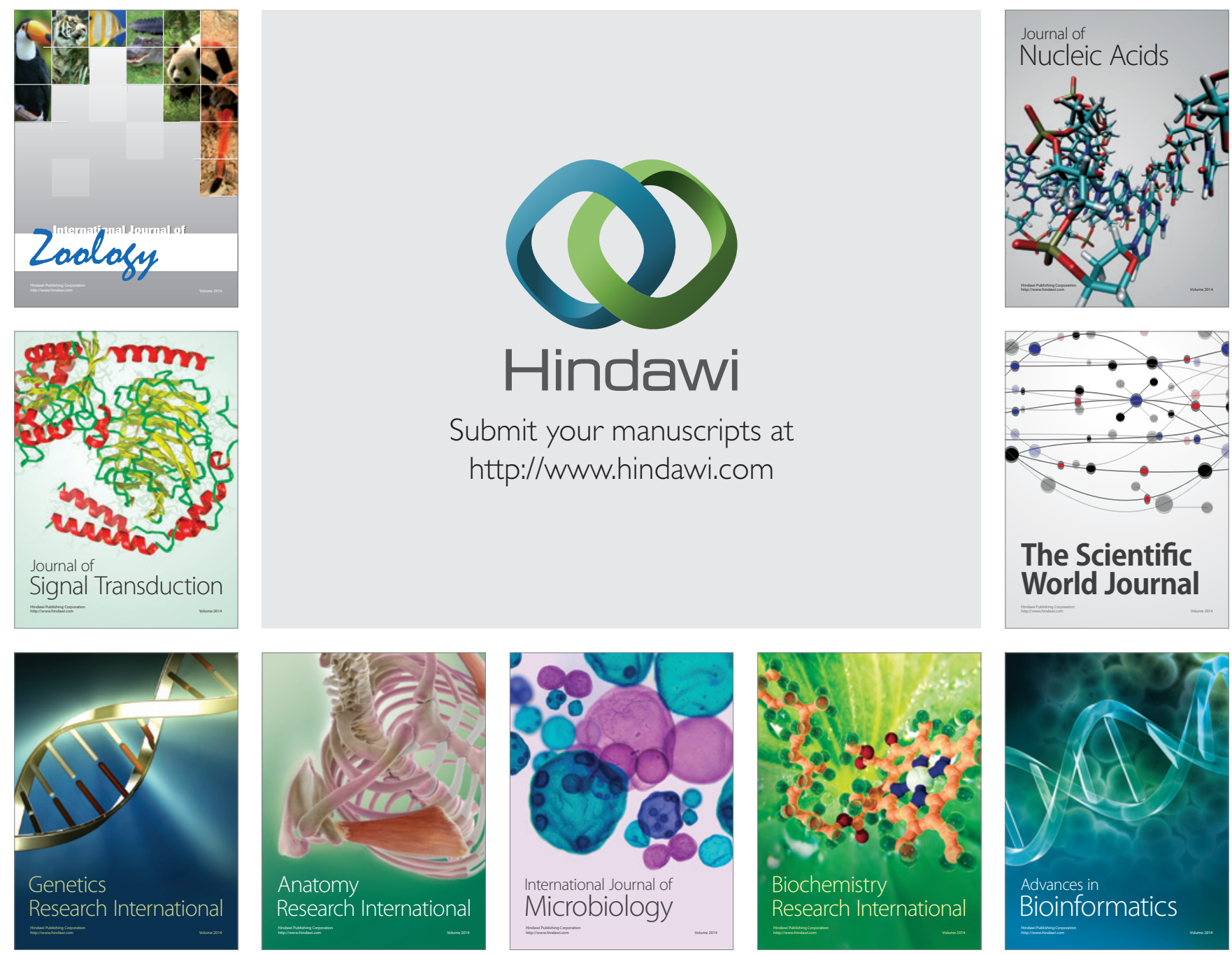

The Scientific World Journal
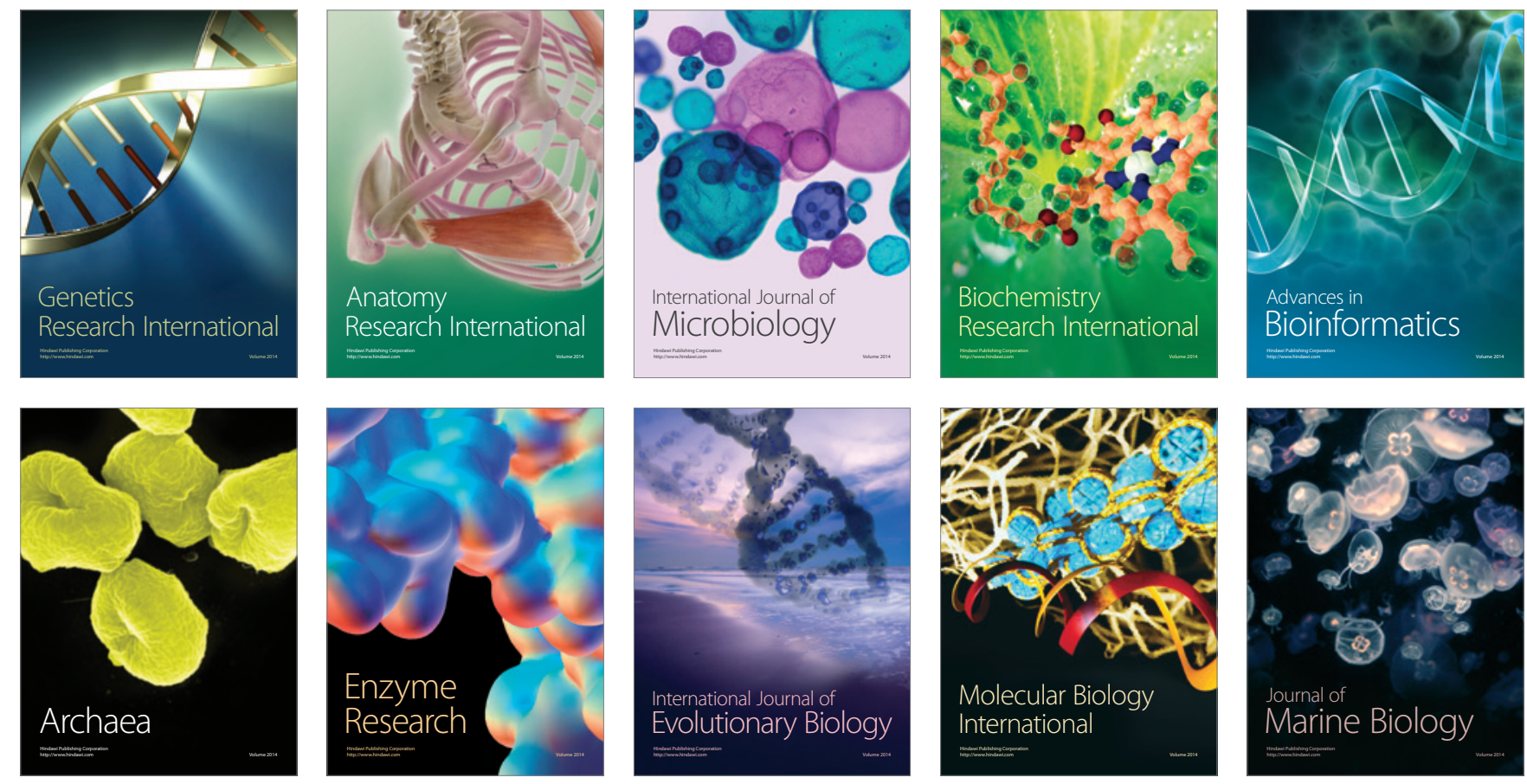